\title{
Aproveitamento agroindustrial da graviola (Annona muricata L.) para produção de licores: avaliação sensorial
}

\author{
Emanuel Neto Alves de Oliveira ${ }^{\mathrm{a} *}$, Dyego da Costa Santos ${ }^{\mathrm{b}}$, Yvana Maria Gomes dos Santos ${ }^{\mathrm{c}}$, \\ Francisco Alexandro Alves de Oliveira ${ }^{\mathrm{d}}$
}

${ }^{\text {a }}$ Instituto Federal do Rio Grande do Norte, Brasil

${ }^{\mathrm{b}}$ Instituto Federal do Acre, Brasil

${ }^{\mathrm{c}}$ Universidade Federal de Campina Grande, Brasil

${ }^{\mathrm{d}}$ Faculdade de Juaziro do Norte, Brasil

*Autor correspondente (emanuel.oliveira16@gmail.com)

\section{N F O}

\section{Keywords}

alcoholic beverage

fruit processing

sensory acceptance
Palavras-chaves bebida alcoólica processamento de frutas aceitação sensorial

\begin{abstract}
A B S T R A C T
Agroindustrial utilization of soursop (Annona muricata L.) for production of liqueurs: sensory evaluation.

The high perishability of the soursop restricts the marketing of fresh fruit to distant markets from producing centers, it is necessary to process it to extend its shelf life. Accordingly, the aim of this work was of preparing liqueurs soursop by using 22 factorial design with three replications at the central point, resulting in 7 experiments, varying concentrations of pulp $(300,400$ and $500 \mathrm{~g})$ sucrose syrup with different levels of soluble solids $\left(50,60\right.$ and $70{ }^{\circ}$ Brix $)$. After processing, the liqueurs were packed in polyethylene packaging and subjected to sensory tests of acceptability, with use of a nine-point scale, with evaluation of sensory attributes of color, aroma, consistency, appearance, taste fruity, alcoholic flavor, sweetness and overall impression. In parallel was performed research purchase intent, using a five-point scale. In the analysis of the influence of independent variables on the response variables was performed regression analysis to obtain the response surfaces from the data of sensory evaluation. Was verified high acceptability for all formulations acceptability of liqueurs soursop, with average rate of acceptability over $70 \%$. It was evidenced greater preference for samples with higher amounts of soursop pulp and lower alcohol levels. The liqueur processed with larger quantities of pulp had intentions to buy greater than $65 \%$, indicating a market potential.
\end{abstract}

\section{R E S U M O}

A alta perecibilidade da graviola restringe a comercialização da fruta in natura a mercados mais distantes dos centros produtores, sendo necessário processá-la para estender sua vida útil. Nesse sentido, objetivouse elaborar licores de graviola mediante utilização de planejamento experimental fatorial 22, com três repetições no ponto central, resultando em 7 tratamentos, variando-se as concentrações de polpa $(300,400$

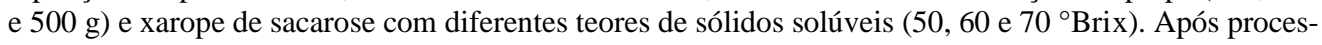
samento, os licores foram acondicionados em embalagens de polietileno e submetidos aos testes sensoriais de aceitação, com uso de uma escala de nove pontos, com avaliação dos atributos sensoriais de cor, aroma, consistência, aparência, sabor frutal, sabor alcoólico, doçura e impressão global. Paralelamente efetuouse investigação da intenção de compra, com uso de uma escala de cinco pontos. Na análise da influência das variáveis independentes sobre as variáveis respostas foi realizada análise de regressão para a obtenção de superfícies de resposta, a partir dos dados da avaliação sensorial. Verificou-se elevada aceitabilidade para todos os tratamentos de licores de graviola, com índices de aceitabilidade médios superiores a $70 \%$. Evidenciou-se maior preferência pelas amostras com maiores quantidades de polpa de graviola e menores teores alcoólicos. Os licores processados com as maiores quantidades de polpa apresentaram intenções de compra superiores a $65 \%$, indicando potencial mercadológico. 


\section{INTRODUÇÃO}

O Nordeste brasileiro apresenta condições favoráveis para o cultivo de várias espécies frutíferas, com importância econômica real ou potencial para a agroindústria. Dentre as várias espécies conhecidas, a gravioleira (Annona muricata L.) tem se destacado devido as suas características sensoriais de sabor e aroma. Pertence à família Annonaceae, da qual fazem parte cerca de 75 gêneros e mais de 600 espécies, em que somente três gêneros produzem frutos comestíveis, sendo os da Annona e Rollinia os de maior importância comercial, em virtude da qualidade dos frutos (Miranda et al., 2011).

$\mathrm{O}$ fruto da gravioleira, quando em temperatura ambiente e colhido na maturidade fisiológica, completa o amadurecimento em até seis dias. Esse curto período de conservação após a colheita faz com que a graviola seja altamente perecível. Isto tem sido atribuído ao padrão respiratório climatérico do fruto, caracterizado por mais de um ponto máximo (Paull, 1982). Isso tem sido responsável por altos índices de perdas e por dificuldades no abastecimento de mercados tradicionais e potenciais de consumo da fruta fresca (Lima et al., 2010). Como alternativa para o aproveitamento agroindustrial da graviola, deve-se considerar seu aproveitamento para elaboração de licores, o que evitaria perdas por perecibilidade.

A elaboração de licores de graviola poderá suprir a necessidade de consumidores que anseiam por novidades no setor alimentício e de bebidas, além de agregar valor ao fruto e o disponibilizar a mercados mais distantes das regiões produtoras. Estão disponíveis na literatura trabalhos envolvendo o processamento da graviola para elaboração de derivados como sucos (Quek et al., 2013), néctares (Peters et al., 2001), polpas (Miranda et al., 2011), geleias (Orsi et al., 2012) e graviola em pó (Ceballos et al., 2012). Entretanto, não foram encontradas referências do uso dos frutos da gravioleira para produção de licores.

O licor é o produto obtido pela mistura de álcool, água, açúcar e substâncias que lhe fornecem aroma e sabor, em medidas adequadas, sem que haja fermentação durante sua elaboração (Viera et al., 2010). De acordo com o Decreto n. 6.871, de 4 de junho de 2009 (Brasil, 2009), licor é a bebida com graduação alcoólica de 15 a $54 \%$ em volume, a $20^{\circ} \mathrm{C}$, com percentual de açúcar superior a $30 \mathrm{~g} / \mathrm{L}$, elaborado com álcool etílico potável de origem agrícola, destilado alcoólico simples de origem agrícola ou ainda bebidas alcoólicas, adicionada de extrato ou substâncias de origem vegetal ou animal, substâncias aromatizantes, saborizantes, corantes e outros aditivos permitidos em ato administrativo complementar.

A produção de licores, de acordo com Teixeira et al. (2010), constitui uma forma de contornar os problemas relacionados à comercialização de produtos perecíveis e aqueles que possuem aspectos visuais e formas inferiores aos exigidos pelo mercado de frutas frescas, mas que se encontra em bom estado de conservação e com excelente valor sensorial e nutricional. Além disso, é uma alternativa para enfrentar os problemas relacionados ao excesso de produção e baixos preços praticados em alguns períodos. Teixeira et al. (2005) ainda relataram que o processamento dessas bebidas requer tecnologia simples, o produto final é comercializado em temperatura ambiente e apresenta extensa vida-de-prateleira.

Ante o exposto e considerando-se a necessidade de estudos que explorem o potencial mercadológico de frutas, lhes agregando, dessa forma, valor econômico, objetivou-se aproveitar agroindustrialmente frutos da graviola para produção de licores e avaliar a aceitação sensorial das bebidas produzidas.

\section{MATERIAL E MÉTODOS}

Foram utilizadas frutas da gravioleira em estágio de maturação maduros provenientes de pequenos produtores da cidade de Campina Grande - PB $\left(07^{\circ}\right.$ $13^{\prime} 50^{\prime \prime} \mathrm{S}$ e $35^{\circ} 52^{\prime} 52^{\prime \prime} \mathrm{W}$ ), destilado alcoólico de origem agrícola (vodka) com graduação alcoólica de $39 \%$ (v/v) e xarope de sacarose com diferentes concentrações de sólidos solúveis totais $(50,60$ e $70{ }^{\circ}$ Brix) elaborado por concentração em fogo brando da solução de açúcar cristal e água.

As graviolas foram recepcionadas no laboratório, selecionadas para remoção de frutas injuriadas e sujidades, lavadas em água corrente, sanitizadas em solução clorada (200 ppm por $15 \mathrm{~min}$ ) e, posteriormente, submetidas a uma nova lavagem para remoção do cloro residual. Em seguida, as frutas foram secas naturalmente em bancada de laboratório e descascadas manualmente com auxílio de facas de aço inoxidável, separando-se a polpa das sementes e cascas. A polpa foi homogeneizada em liquidificador doméstico, envasada em sacos de polietileno de baixa densidade e estocada em freezer horizontal a $-18^{\circ} \mathrm{C}$ até o início dos experimentos.

No processamento dos licores de graviola, utilizou-se o planejamento experimental fatorial $2^{2}$, com três repetições no ponto central, resultando em 7 tratamentos (Tabela 1), com o objetivo de analisar a influência das variáveis independentes (concentrações de polpa e xaropes de sacarose com diferentes teores de sólidos solúveis totais) sobre as variáveis respostas (atributos sensoriais). 
Tabela 1 - Matriz de planejamento fatorial utilizada para o processamento dos licores de graviola.

\begin{tabular}{lcccc}
\hline \multirow{2}{*}{ Tratamentos } & \multicolumn{2}{c}{ Valores codificados } & \multicolumn{2}{c}{ Valores reais } \\
\cline { 2 - 5 } & $\mathbf{x}_{\mathbf{1}}$ & $\mathbf{x}_{\mathbf{2}}$ & Polpa de graviola (g) & SST do xarope $\left({ }^{\circ} \mathbf{B r i x}\right)^{*}$ \\
\hline L1 & -1 & -1 & 300 & 50 \\
L2 & +1 & -1 & 500 & 50 \\
L3 & -1 & +1 & 300 & 70 \\
L4 & +1 & +1 & 500 & 70 \\
L5 & 0 & 0 & 400 & 60 \\
L6 & 0 & 0 & 400 & 60 \\
L7 & 0 & 0 & 400 & 60 \\
\hline
\end{tabular}

L1, L2...L7 - Licor de graviola; SST - sólidos solúveis totais; *Utilizou-se $400 \mathrm{~mL}$ de xarope em cada tratamento.

A polpa de graviola foi previamente descongelada sob refrigeração em geladeira doméstica, fracionada conforme tabela 1 , misturada com $500 \mathrm{~mL}$ de vodka e submetida, em recipientes de vidro previamente esterilizados e providos de tampa, a uma maceração a frio por um período de vinte dias, conforme o tempo mínimo recomendado pelo dossiê técnico para a produção de licores de graviola (Carvalho, 2007). Segundo Oliveira e Santos (2011), a maceração baseia-se em uma operação unitária que consiste em retirar e/ou extrair de um corpo, certas substâncias que são consideradas princípios ativos (flavor) por meio da adição de um solvente (álcool) durante certo período, tais como compostos aromáticos, pigmentos e componentes nutricionais.

Após a maceração, os extratos hidroalcoólicos de graviola (macerado) foram filtrados em peneira com uma fina camada de algodão para remoção de resíduos provenientes da polpa e adicionados de $400 \mathrm{~mL}$ de xarope de sacarose com diferentes teores de sólidos solúveis totais (Tabela 1), com a finalidade de promover a elevação das concentrações de açúcares e reduzir os seus teores alcoólicos. As misturas foram homogeneizadas e submetidas a um envelhecimento rápido em banho-maria a $60^{\circ} \mathrm{C}$ por 2 horas, nos mesmos potes onde ocorreram as macerações, com o objetivo de desenvolver precursores de aroma e sabor, de modo a melhorar a qualidade da bebida (Alzugaray e Alzugaray, 1986). Na sequência, os licores foram resfriados em temperatura ambiente, acondicionados em garrafas plásticas de polietileno de baixa densidade providas de tampas enroscadas e submetidos às análises de açúcares totais pela técnica titulométrica com solução de Fehling sob aquecimento, sendo precedido de hidrólise ácida da amostra antes da titulação; teor alcoólico, quantificado pela destilação da amostra e determinação da densidade do álcool destilado a 20 ${ }^{\circ} \mathrm{C}$, ambos segundo métodos do Instituto Adolfo Lutz (2008), e aos testes sensoriais.

A avaliação sensorial dos licores de graviola foi realizada mediante aprovação por Comitê de Ética em Pesquisa da Universidade Estadual da Paraíba (UEPB) sob processo CAAE $n^{\circ}$ 0104.0.133.00012. A mesma foi conduzida com equipe de 38 julgadores não treinados composta por homens e mulheres com idades compreendidas entre 18 e 50 anos, segundo normas da Associação Brasileira de Normas Técnicas (ABNT, 1993). Aproximadamente $20 \mathrm{~mL}$ de cada tratamento foram servidos em temperatura ambiente $\left(\sim 26^{\circ} \mathrm{C}\right)$ em copos plásticos codificados com três dígitos aleatórios, acompanhados de água mineral para limpeza do palato.

Aplicou-se teste de aceitação (Dutcosky, 2011), com uso de escala hedônica estruturada mista de nove pontos, com escores variando entre 1 (desgostei muitíssimo) e 9 (gostei muitíssimo), avaliandose os atributos sensoriais de cor, aroma, consistência, aparência, sabor frutal, sabor alcoólico, doçura, e impressão global. Adicionalmente foi calculado o índice de aceitabilidade (Equação 1) para cada atributo avaliado (Gularte, 2009) e também a média entre todos os índices de aceitabilidade, para cada tratamento, a fim de obter o licor de graviola mais aceito. Verificou-se ainda a intenção de compra dos licores com uso de escala estruturada mista de cinco pontos, com escores compreendidos entre 1 (certamente não compraria) e 5 (certamente compraria o produto).

Índice de aceitabilidade $(\%)=\frac{\mathrm{M}}{\mathrm{N}} \times 100$

Em que:

M média do somatório dos resultados dos julgadores;

$\mathrm{N}$ número de pontos utilizados na escala de avaliação.

$\mathrm{Na}$ análise da influência das variáveis independentes sobre as variáveis respostas foi realizada análise de regressão, utilizando-se o programa 
computacional Statistica versão 6.0, para a obtenção de superfícies de resposta a partir dos dados da avaliação sensorial.

\section{RESULTADOS E DISCUSSÃO}

Os teores alcoólicos e os açúcares totais dos licores de graviola foram de 15,03 (L2) a 16,69\% v/v (L1) e de 126,3 (L2) a 179,7 g/L (L3), respectivamente (Figura 1), com todas as bebidas apresentando-se em conformidade com a legislação brasileira (Brasil, 2009), com teor alcoólico dentro da faixa preconizada $\left(15\right.$ a $54 \%$ em volume a $20^{\circ} \mathrm{C}$ ) e um percentual de açúcar superior ao mínimo estabelecido que é de $30 \mathrm{~g} / \mathrm{L}$. De acordo com a legislação citada (Brasil, 2009), os licores de graviola foram classificados como licores finos ou doces, por terem apresentado teores de açúcares compreendidos entre 100 e $300 \mathrm{~g} / \mathrm{L}$. Os licores elaborados com xarope com $70{ }^{\circ}$ Brix (L3 e L4) revelaram os maiores conteúdos de açúcares, o que já era esperado, uma vez que apresentavam maior teor de sólidos em solução. Enquanto que as bebidas processadas com a menor proporção de polpa (L1 e L3) apresentaram os maiores teores alcoólicos. Isso está relacionado à menor adição da graviola que promoveu, em consequência, menor diluição do álcool. Oliveira \& Santos (2011) e Teixeira et al. (2005) reportaram teores alcoólicos próximos aos observados neste estudo em licores de açaí (16\% v/v) e de banana $(17,80$ a $18,77 \%$ v/v), respectivamente. Já Almeida et al. (2012) e Vacca et al. (2003) encontraram teores de açúcares totais bem mais elevados ao elaborarem licores de cascas de tangerina ( 350 $\mathrm{g} / \mathrm{L})$ e murta $(251,2$ e $257,5 \mathrm{~g} / 100 \mathrm{~mL})$, respectivamente.

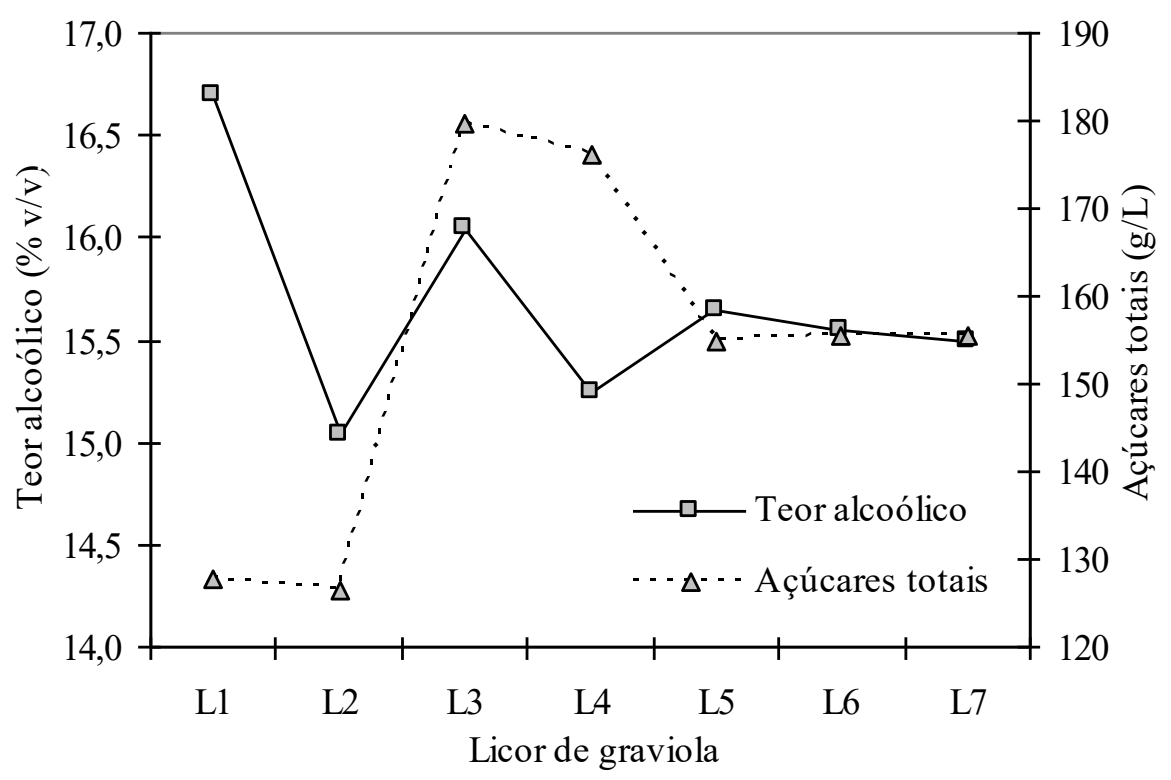

Figura 1 - Teores alcoólicos e açúcares totais encontrados nos licores de graviola.

Têm-se na Tabela 2 os resultados médios da avaliação sensorial dos licores de graviola. Estes revelaram, para o atributo de cor, escores compreendidos entre 6,74 (L2) a 6,47 (L1 e L5), sendo as bebidas processadas com maior concentração de polpa as que apresentaram os maiores valores absolutos (Tabela 2). Esses resultados podem estar relacionados à etapa de maceração, já que as maiores concentrações de polpa promoveram maiores arrastes de constituintes químicos responsáveis pela coloração característica da graviola, como pigmentos. De acordo com Tocchini \& Mercadante (2001), o impacto visual causado pela cor sobrepõe-se a todos os outros atributos, fazendo desse atributo um dos mais importantes na comercialização de alimentos e constituindo, assim, no primeiro critério de aceitação ou rejeição de um produto.

$\mathrm{O}$ atributo sensorial de aroma teve notas oscilando entre 6,32 (L3) e 6,75 (L7), com as bebidas processadas com as maiores concentrações de polpa relevando os maiores escores (Tabela 2). Assim como relatado para a cor, a maior proporção de polpa utilizada favoreceu a ocorrência de maior extração de compostos aromáticos na etapa de maceração, o que ajuda a justificar as maiores notas. Notou-se ainda que os licores que apresentaram os maiores teores alcoólicos (Figura 1) foram também os que obtiveram as menores notas para o aroma, o que segundo Viana et al. (2011) é devido à capacidade do álcool em inibir, em parte, o aroma característico das frutas. A consistência apresentou esco- 
res variando entre 6,26 (L3) a 7,08 (L2), com os licores formulados com as maiores proporções de polpa apresentando os maiores valores para esse atributo (Tabela 2). Como a graviola apresenta em sua composição quantidades consideráveis de amido e substâncias pécticas (Lima et al., 2010), esses constituintes em solução poderiam favorecer o aumento de consistência das bebidas, o que justifica as maiores notas atribuídas aos licores elaborados com as maiores quantidades de graviola.

Tabela 2 - Resultados médios da análise sensorial dos licores de graviola.

\begin{tabular}{ccccccccc}
\hline $\begin{array}{c}\text { Trata- } \\
\text { mentos }\end{array}$ & Cor & Aroma & $\begin{array}{c}\text { Consis- } \\
\text { tência }\end{array}$ & $\begin{array}{c}\text { Aparên- } \\
\text { cia }\end{array}$ & $\begin{array}{c}\text { Sabor } \\
\text { frutal }\end{array}$ & $\begin{array}{c}\text { Sabor al- } \\
\text { coólico }\end{array}$ & $\begin{array}{c}\text { Do- } \\
\text { çura }\end{array}$ & $\begin{array}{c}\text { Impressão } \\
\text { global }\end{array}$ \\
\hline L1 & 6,47 & 6,55 & 6,74 & 6,63 & 6,92 & 6,29 & 6,79 & 6,92 \\
L2 & 6,74 & 6,68 & 7,08 & 6,61 & 7,08 & 6,63 & 7,29 & 7,26 \\
L3 & 6,63 & 6,32 & 6,26 & 6,58 & 6,71 & 6,37 & 6,47 & 6,84 \\
L4 & 6,71 & 6,74 & 6,92 & 6,97 & 7,47 & 6,71 & 7,11 & 7,21 \\
L5 & 6,47 & 6,71 & 6,55 & 6,87 & 7,08 & 6,71 & 6,95 & 7,05 \\
L6 & 6,50 & 6,72 & 6,53 & 6,90 & 7,10 & 6,71 & 6,90 & 7,00 \\
L7 & 6,49 & 6,75 & 6,50 & 6,89 & 7,11 & 6,70 & 6,94 & 7,04 \\
\hline
\end{tabular}

L1, L2... L5 - Licor de graviola.

No tocante a aparência, verificou-se escores variando entre 6,58 (L3) e 6,97 (L4), com o licor elaborado com a maior concentração de polpa e com xarope com o maior teor de sólidos solúveis totais revelando a maior nota (Tabela 2). Isso pode estar relacionado à combinação entre os atributos de cor e de consistência, uma vez que, geralmente, licores com a coloração mais próxima à da fruta e com maior viscosidade (promovida pela elevada proporção de polpa somada à maior concentração de açúcares) são mais atrativos ao consumidor. $\mathrm{O}$ atributo sensorial de sabor frutal evidenciou notas compreendidas entre 6,71 (L3) e 7,47 (L4), com as amostras formuladas com as maiores quantidades de polpas revelando escores superiores a 7,0 (Tabela 2). Esse resultado já era esperado, uma vez que maiores proporções de fruta proporcionam, na etapa de maceração, maior extração de princípios ativos responsáveis pelo flavor. Em relação ao sabor alcoólico, os escores variaram de 6,29 (L1) a 6,71 (L4 a L6), com as bebidas elaboradas com as maiores proporções de polpa apresentando as maiores notas (Tabela 2). Isso demonstra a preferência por parte dos consumidores por licores com as menores graduações alcoólicas (Figura 1), uma vez que o sabor do álcool pode mascarar o sabor da fruta (Penha et al., 2003). Teixeira et al. (2007) realizaram testes de aceitação em licores de banana e verificaram, para o atributo sabor alcoólico, escores com uma faixa de variação superior $(6,0$ a 8,0$)$ a registrada neste trabalho.

A doçura apresentou escores oscilando entre
6,47 (L3) a 7,29 (L2), com apenas as bebidas formuladas com a maior quantidade de polpa apresentando os maiores escores para esse atributo (Tabela 2), o que, provavelmente, pode estar relacionado ao balanço mais adequado entre os sólidos solúveis totais (SST) e a acidez total titulável (ATT), relação denominada de ratio. Quanto maior o valor de SST e menor a ATT, mais elevada será a sensação de doçura. Considerando-se que os licores L2 e L4 apresentaram os menores teores de SST, devido às menores concentrações de açúcares em solução (Figura 1), e, possivelmente, as maiores ATT, devido à maior proporção de polpa (Tabela 1), estima-se que essas amostras foram as menos doces. Houve, portanto, preferência por parte dos consumidores por bebidas com menor doçura, provavelmente, por preservar melhor as características originais da fruta. Quanto ao atributo impressão global, observou-se notas compreendidas entre 6,84 (L3) e 7,26 (L2), com os tratamentos processados com os maiores teores de polpa apresentando escores, para esse atributo, superiores a 7,0 (Tabela 2).

Estão apresentados na Figura 2 os índices de aceitabilidade de todos os atributos sensoriais dos licores de graviola. Todos os atributos sensoriais investigados apresentaram índices de aceitabilidade superiores a 70\%, com exceção dos atributos consistência para o tratamento L3 e sabor alcoólico para a bebida L1, que revelaram índices de aceitabilidade superiores a $69,50 \%$. 

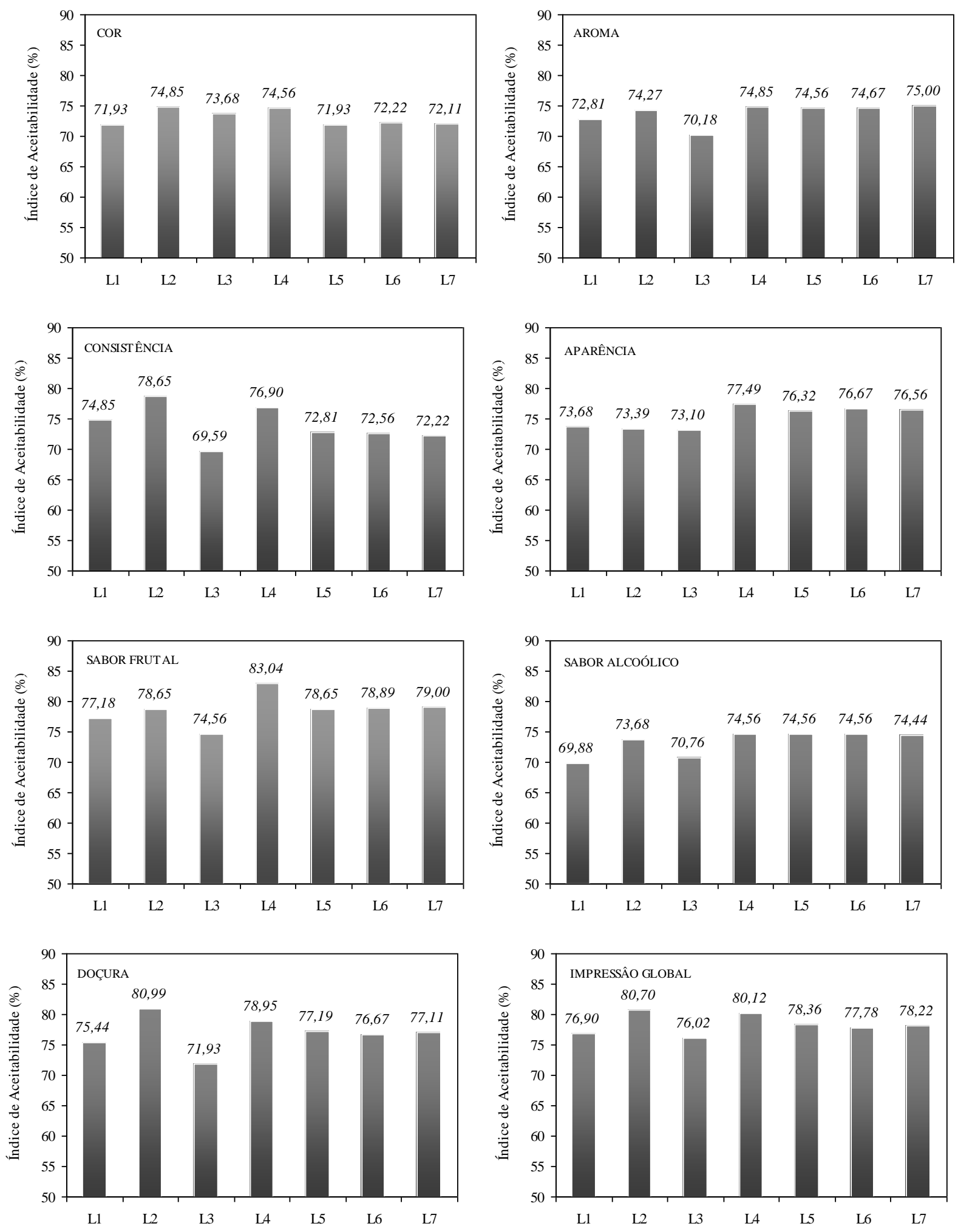

Figura 2 - Índices de aceitabilidade dos atributos sensoriais dos licores de graviola. 
Considerando-se o índice de aceitabilidade médio de todos os atributos, para cada tratamento (Figura 3), percebe-se que todos os licores de graviola apresentaram índices de aceitabilidade médios superiores a $70 \%$. Contudo, ressalta-se que as maiores aceitabilidades foram evidenciadas nos tratamentos elaborados com a maior concentração de polpa, seguida da bebida formulada com valor médio de graviola e sugerindo maior preferência por parte dos julgadores por licores com baixos teores de álcool (Figura 1) e com maior proporção de fruta, possivelmente por preservar melhor as características do vegetal de origem. De acordo com Dutcosky (2011) e Gularte (2009), o índice de aceitabilidade de 70\% é a porcentagem mínima para que um produto seja considerado aceito, em termos de suas características sensoriais.

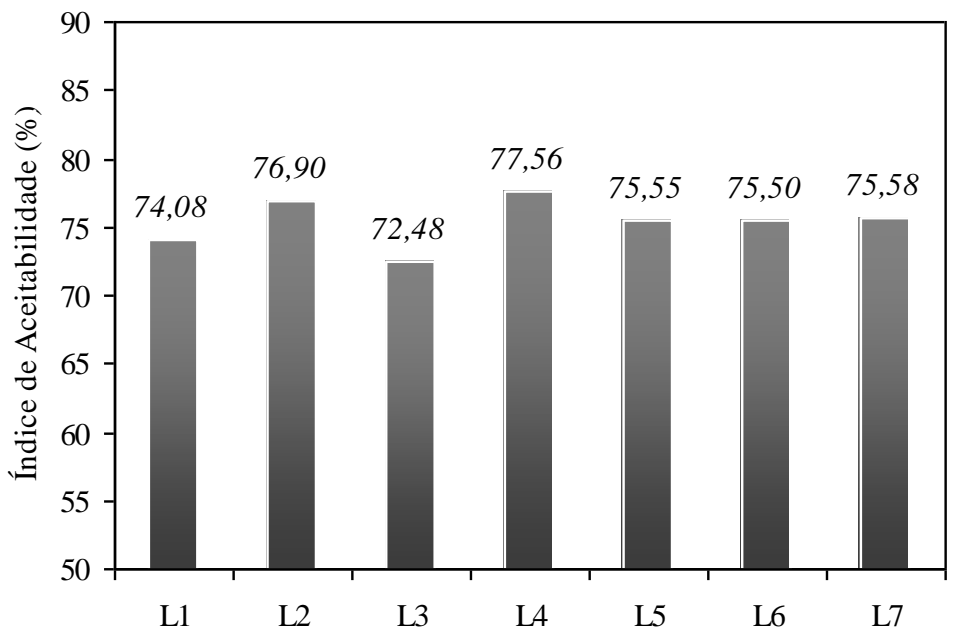

Figura 3 - Índice de aceitabilidade total para todos os atributos sensoriais avaliados dos licores de graviola.

A tabela 3 apresenta a distribuição de frequência para a intenção de compra dos diferentes tratamentos de licores de graviola. Verificou-se que mais de $65 \%$ dos provadores assinalaram que provavelmente ou certamente comprariam os licores de graviola processados com as maiores quantidades de polpa (400 e $500 \mathrm{~g}$ ), confirmando a maior preferência por essas bebidas (Tabela 3). Esses resultados evidenciam o potencial mercadológico da bebida elaborada. Todavia, devem ser conduzidos novos estudos com o objetivo de ajustes de formulações, para se aprimorar a qualidade sensorial dos licores.

Tabela 3 - Distribuição da frequência (\%) de intenção de compra dos licores de graviola.

\begin{tabular}{cccccc}
\hline \multirow{2}{*}{ Tratamentos } & \multicolumn{5}{c}{ Escores de intenção de compra } \\
\cline { 2 - 6 } & $\mathbf{1}$ & $\mathbf{2}$ & $\mathbf{3}$ & $\mathbf{4}$ & $\mathbf{5}$ \\
\hline L1 & 5,26 & 13,16 & 34,21 & 31,58 & 15,79 \\
L2 & 2,63 & 5,26 & 26,32 & 36,84 & 28,95 \\
L3 & 0,00 & 7,89 & 34,21 & 42,11 & 15,79 \\
L4 & 0,00 & 7,89 & 23,69 & 34,21 & 34,21 \\
L5 & 5,26 & 10,53 & 15,79 & 44,74 & 23,68 \\
L6 & 5,26 & 7,89 & 15,79 & 47,37 & 23,69 \\
L7 & 2,63 & 10,52 & 13,16 & 47,37 & 26,32 \\
\hline
\end{tabular}

L1, L2...L5 - Licores de graviola; (Escores: 1 - certamente eu não compraria; 3 - talvez eu compraria; 5 -certamente eu compraria).

Têm-se na tabela 4 as análises de regressão dos atributos sensoriais avaliados nos licores de graviola. As mesmas forneceram modelos de $1^{\text {a }}$ ordem, com uma interação e intervalo de confiança de $95 \%$. Os modelos matemáticos ajustados aos dados dos atributos sensoriais de sabor frutal, doçura e impressão global foram significativos e preditivos, com valores da relação de F calculado e F tabelado
$\left(\mathrm{F}_{\mathrm{c}} / \mathrm{F}_{\text {tab }}\right)$ superiores a 4,0. Esses modelos apresentaram ainda coeficientes de determinação $\left(\mathrm{R}^{2}\right)$ superiores a 0,97 , atestando bom ajuste aos dados experimentais. Em relação aos atributos sensoriais de cor, aroma, consistência, aparência e sabor alcoólico, não foram detectados bons ajustes dos modelos matemáticos aos dados, com $\mathrm{R}^{2}$ inferiores a 0,82 e valores da relação $F_{c} / F_{\text {tab }}$ inferiores a 1,0. 
Observa-se na Figura 4 os resultados da influência dos fatores concentração de polpa de graviola $(\mathrm{P})$, xarope de sacarose com diferentes teores de sólidos solúveis totais $(\mathrm{X})$ e sua interação $(\mathrm{P} / \mathrm{X})$ sobre as variáveis respostas (atributos sensoriais) da avaliação sensorial dos licores de graviola. $\mathrm{O}$ fator polpa (P) apresentou efeito significativo sobre todas as variáveis respostas pesquisadas. Em relação ao fator xarope (X), este não revelou efeito significativo para os atributos de cor, aroma e impressão global, enquanto que a interação entre os fatores $\mathrm{P} / \mathrm{X}$ não apresentou efeito significativo para as respostas sabor alcoólico, doçura e impressão global, o que indica que esses atributos sensoriais não foram influenciados por esses fatores.

Tabela 4 - Resultados das análises de regressão para os atributos sensoriais avaliados dos licores de graviola.

\begin{tabular}{lccccl}
\hline \multicolumn{1}{c}{ Resposta } & $\mathbf{R}^{\mathbf{2}}$ & $\mathbf{F}_{\mathbf{c}}$ & $\mathbf{F}_{\text {tab }}$ & $\mathbf{F}_{\mathbf{c}} / \mathbf{F}_{\text {tab }}$ & \multicolumn{1}{c}{ Equação } \\
\hline Cor & 0,5264 & 1,11 & 9,28 & 0,12 & $4,887857+0,003725 \mathrm{P}+0,02225 \mathrm{X}-0,000048 \mathrm{P} / \mathrm{X}$ \\
Aroma & 0,7140 & 2,50 & 9,28 & 0,27 & $8,083571-0,002975 \mathrm{P}-0,03325 \mathrm{X}+0,000073 \mathrm{P} / \mathrm{X}$ \\
Consistência & 0,8133 & 4,36 & 9,28 & 0,47 & $8,534286-0,0023 \mathrm{P}-0,048 \mathrm{X}+0,00008 \mathrm{P} / \mathrm{X}$ \\
Aparência & 0,6187 & 1,62 & 9,28 & 0,17 & $8,403571-0,005225 \mathrm{P}-0,03325 \mathrm{X}+0,000103 \mathrm{P} / \mathrm{X}$ \\
Sabor frutal & 0,9840 & 61,41 & 9,28 & 6,62 & $9,477143-0,0067 \mathrm{P}-0,0555 \mathrm{X}+0,00015 \mathrm{P} / \mathrm{X}$ \\
Sabor alcoólico & 0,6247 & 1,66 & 9,28 & 0,18 & $5,668571+0,0017 \mathrm{P}+0,004 \mathrm{X}$ \\
Doçura & 0,9955 & 219,69 & 9,28 & 23,67 & $7,371429+0,00075 \mathrm{P}-0,0265 \mathrm{X}+0,000035 \mathrm{P} / \mathrm{X}$ \\
Impressão global & 0,9798 & 48,39 & 9,28 & 5,21 & $6,710714+0,001325 \mathrm{P}-0,00625 \mathrm{X}+0,000008 \mathrm{P} / \mathrm{X}$ \\
\hline
\end{tabular}

$\mathrm{F}_{\mathrm{c}}$ - F calculado; $\mathrm{F}_{\text {tab }}$ - F tabelado; $\mathrm{P}$ - Polpa de graviola; $\mathrm{X}$ - Xarope com diferentes teores de sólidos solúveis totais.

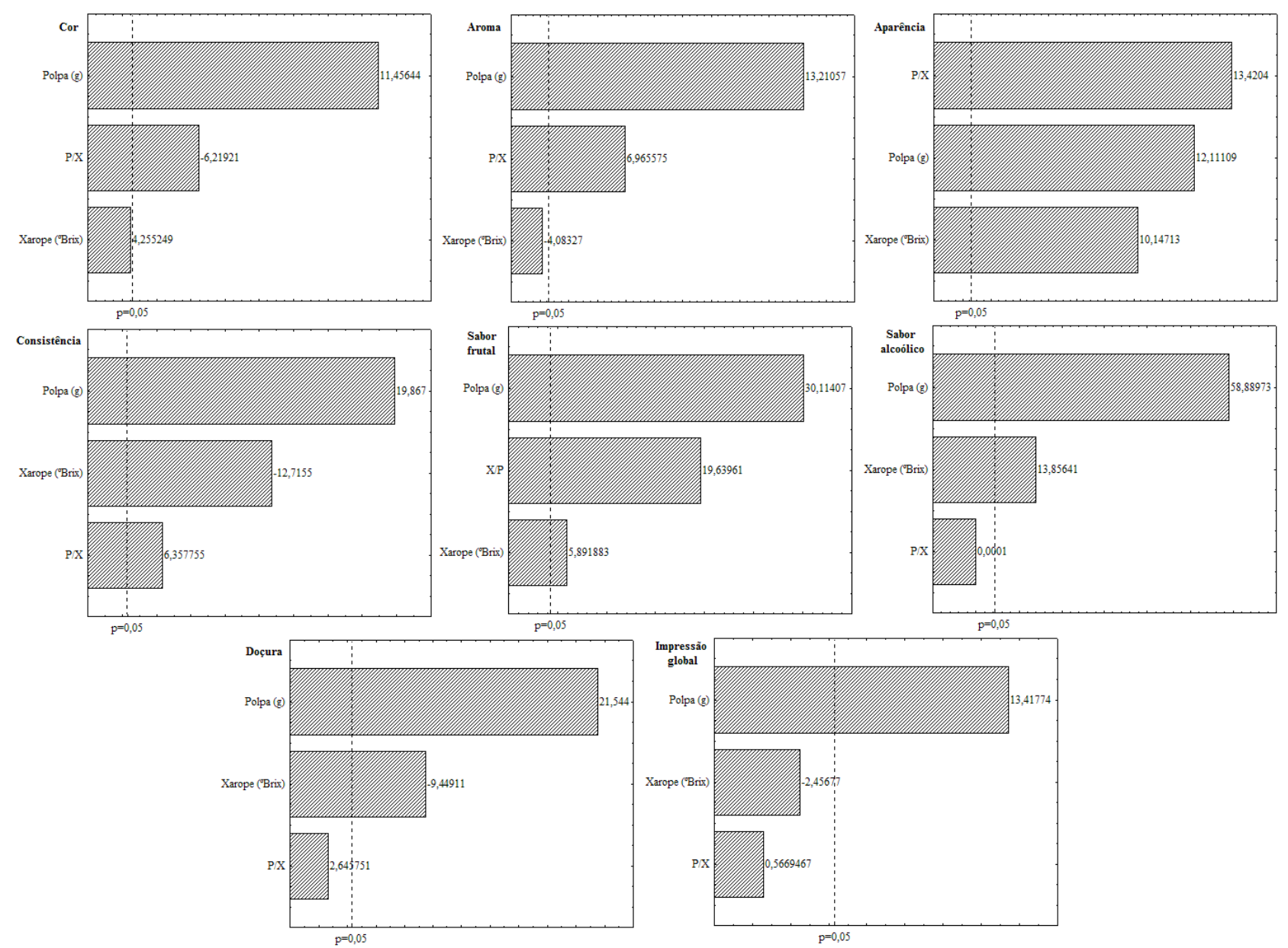

Figura 4 - Diagrama de Pareto para os atributos sensoriais avaliados dos licores de graviola. 
Estão apresentadas na figura 5 as superfícies de resposta dos atributos sensoriais que apresentaram significância estatística na análise da regressão (Tabela 4). Constatou-se que o aumento da concentração de polpa e a redução do teor de sólidos solúveis do xarope promoveram aumentos dos es- concentração de polpa e redução dos sólidos solúveis totais do xarope, o que sugere a preferência por licores menos doces do ponto de vista sensorial. Quanto à impressão global dos licores, verificou-se influência mais direta da concentração de polpa, já que o aumento de sua concentração nas
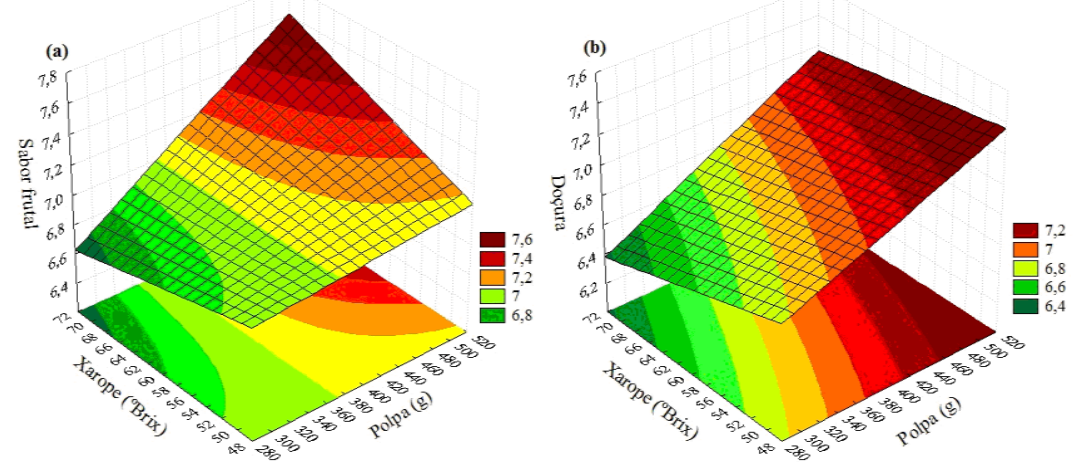

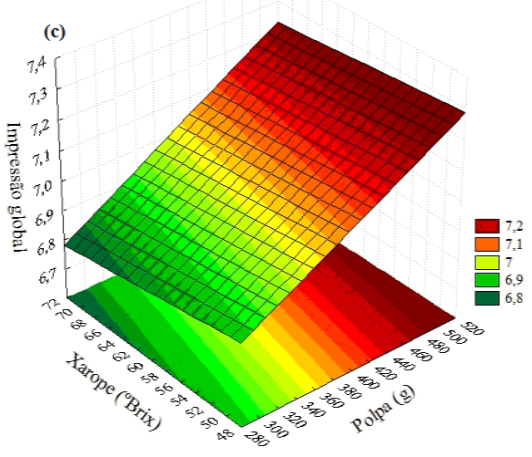

formulações promoveu aumento dos escores, enquanto que o aumento do teor de sólidos solúveis totais do xarope não teve interferência significativa nos resultados. cores de sabor frutal, todavia, o fator polpa apre-
sentou maior influência nesses atributos. $\mathrm{O}$ atributo sensorial de doçura teve as notas da avaliação pelos provadores aumentadas com a elevação da

Figura 5 - Superfícies de resposta para os atributos sensoriais de sabor frutal (a), doçura (b) e impressão global (c) dos licores de graviola

\section{CONCLUSÃO}

Verificou-se elevada aceitabilidade para todos os licores de graviola, com índices de aceitabilidade médios superiores a $70 \%$. Entretanto, houve maior preferência por licores com maiores quantidades de polpa de graviola e menores teores alcoólicos. As intenções de compra superiores a $65 \%$ para os licores de graviola processados com as maiores quantidades de polpa reforçam o potencial mercadológico dessas bebidas, com perspectiva de inserção de um novo produto no mercado.

Todos os atributos sensoriais sofreram efeito significativo do fator polpa (P), enquanto que os atributos de consistência, aparência, sabor frutal, sabor alcoólico e doçura sofreram efeito significativo do fator xarope $(\mathrm{X})$. Os atributos sensoriais de cor, aroma, consistência, aparência e sabor frutal sofreram efeito significativo da interação entre os fatores $\mathrm{P} / \mathrm{X}$.

Os atributos sabor frutal e doçura sofreram influência dos fatores concentração de polpa e teor de sólidos solúveis totais do xarope de sacarose, sendo mais evidente a interferência da variável polpa na aceitação dos provadores. A reposta impressão global foi influenciada pela concentração de polpa, sendo mínima a interferência do xarope nesses resultados.

\section{REFERÊNCIAS BIBLIOGRÁFICAS}

ALMEIDA, E. L.; LIMA, L. C.; BORGES, V. T. N.; MARTINS, R. N.; BATALINI, C. Elaboração de licor de casca de tangerina (Citrus reticulata Blanco), variedade Ponkan, com diferentes concentrações de casca e tempos de processamento. Alimentos e Nutrição, v.23, n.2, p.259-265, 2012.

ALZUGARAY, D.; ALZUGARAY, C. Manuais práticos: licores. $1^{a}$ ed. São Paulo: Editora Três Ltda, 1986. 32p.

ASSOCIAÇÃO BRASILEIRA DE NORMAS TÉCNICAS (ABNT). NBR 12994: Métodos de avaliação sensorial de alimentos e bebidas. São Paulo: ABNT, 1993. 2p.

BRASIL. Ministério da Agricultura, Pecuária e Abastecimento. Decreto n. 6.871, de 4 de junho de 2009. Regulamenta a lei n. 8.918 de 14 de julho de 1994. Dispõe sobre a padronização, a classificação, o registro, a inspeção, a produção e a fiscalização de bebidas. Diário Oficial [da] República Federativa do Brasil, Brasília, DF, 2009.

CARVALHO, R.F. Produção de licores. Dossiê técnico. Rede de Tecnologia da Bahia: RETEC/BA, 2007. 27 p.

CEBALLOS, A.M.; GIRALDO, G.I.; ORREGO, C.E. Effect of freezing rate on quality parameters of freeze dried soursop fruit pulp. Journal of Food Engineering, v.111, n.2, p.360-365, 2012.

DUTCOSKY, S.D. Análise sensorial de alimentos. $3^{\mathrm{a}}$ ed. $\mathrm{Cu}-$ ritiba: Editora Universitária Champagnat, 2011. 426 p.

GULARTE, M.A. Análise sensorial. Pelotas: Editora Universitária da Universidade Federal de Pelotas, 2009. 66 p. 
INSTITUTO ADOLFO LUTZ. Normas analíticas, métodos químicos e físicos para análises de alimentos. $4^{\mathrm{a}}$ ed. $1^{\mathrm{a}} \mathrm{ed}$. Digital, São Paulo: IAL, 2008. 1020p.

LIMA, M.A.C.; ALVES, R.E.; FILGUEIRAS, H.A.C. Comportamento respiratório e amaciamento de graviola ( $A n$ nona muricata L.) após tratamentos pós-colheita com cera e 1-metilciclopropeno. Ciência e Agrotecnologia, v.34, n.1, p.155-162, 2010.

MIRANDA, V.A.M.; QUEIROZ, A.J.M.; FIGUEIRÊDO, R.M.F.; SANTOS, D.C. Viscosidade aparente de polpas de graviola com diferentes concentrações. Revista Brasileira de Produtos Agroindustriais, v.13, n. Especial, p.363-374, 2011.

OLIVEIRA, E.N.A.; SANTOS, D.C. Processamento e avaliação da qualidade de licor de açaí (Euterpe oleracea Mart.). Revista do Instituto Adolfo Lutz, v.70, n.4, p.534-41, 2011.

ORSI, D.C.; CARVALHO, V.S.; NISHI, A.C.F.; DAMIANI, C.; ASQUIERI, E.R. Use of sugar apple, atemoya and soursop for technological development of jams - chemical and sensorial composition. Ciência e Agrotecnologia, v.36, n.5, p.560-566, 2012.

PAULL, R.E. Postharvest variation in composition of soursop (Annona muricata L.) fruit in relation to respiration and ethylene production. Journal of the American Society for Horticultural Science, v.107, n.4, p.582-585, 1982.

PENHA, E.M.; MODESTA, R.C.D.; GONÇALVES, E.B.; SILVA, A.L.S.; MORETTI, R.H. Efeito dos teores de álcool e açúcar no perfil sensorial de licor de acerola. Brazilian Journal of Food Technology, v.6, n.1, p.33-42, 2003.

PETERS, M.; BADRE, N.; COMISSIONG, E. Processing and quality evaluation of soursop (Annona muricata $\mathrm{L}$ ) nectar. Journal of Food Quality, v.24, n.5, p.361-374, 2001.

QUEK, M.C.; CHIN, N.L.; YUSOF, Y.A. Modelling of rheological behaviour of soursop juice concentrates using shear rate temperature concentration superposition. Journal of Food Engineering, v.118, n.4, p.380-386, 2013.

TEIXEIRA, L.J.Q.; RAMOS, A.M.; CHAVES, J.B.P.; SILVA, P.H.A.; STRINGHETA, P.C. Avaliação tecnológica da extração alcoólica no processamento de licor de banana. Boletim do Centro de Pesquisa de Processamento de Alimentos, v.23, n.2, p.329-346, 2005.

TEIXEIRA, L.J.Q.; RAMOS, A.M.; CHAVES, J.B.P.; STRINGHETA, P.C. Testes de aceitabilidade de licores de banana. Revista Brasileira de Agrociência, v.13, n.2, p.205-209, 2007.

TEIXEIRA, L.J.Q.; ROCHA, C.T.; JUNQUEIRA, M.S.; SARAIVA, S.H. Determinação da cinética de extração alcoólica no processamento de licor de café. Enciclopédia Biosfera, v.6, n.9, p.1-9. 2010.

TOCCHINI, L.; MERCADANTE, A.Z. Extração e determinação, por CLAE, de bixina e norbixina em caloríficos Ciência e Tecnologia de Alimentos, v.21, n.3, p.43-45, 2001.

VACCA, V.; PIGA, A.; CARO, A.; FENU, P.A.M.; AGAB$\mathrm{BIO}, \mathrm{M}$. Changes in phenolic compounds, colour and antioxidant activity in industrial red myrtle liqueurs during storage. Nahrung/Food, v.47, n.6, p.442-447, 2003.
VIANA, L.F.; MUNHOZ, C.L.; SOUZA, A.R.M.; SANTANA, L.M.; MACIEL, V.; CALIARI, M. Development and characterization of the tangerine peel liquor with different alcoholic bases. Acta Scientiarum. Technology, v.33, n.1, p.95-100, 2011.

VIERA, V.B.; RODRIGUES, J.B.; BRASIL, C.C.B.; ROSA, C.S. Produção, caracterização e aceitabilidade de licor de camu-camu (Myrciaria dubia (H.B.K.) McVaugh). Alimentos e Nutrição, v.21, n.4, p.519-522, 2010. 